\title{
Para além da dupla consciência: Gestão Social e as antessalas epistemológicas
}

\author{
Beyond double consciousness: Social Management and the epistemological anterooms
}

\author{
Carlos Eduardo Justen ${ }^{1}$ \\ Luís Moretto Neto ${ }^{2}$ \\ Paulo Otolini Garrido ${ }^{3}$
}

\section{Resumo}

A partir da noção de dupla consciência, observada na obra The souls of black folk (1903), de W. E. B. Du Bois e utilizada como metarreferência discursiva, este artigo, como ensaio teórico, objetiva estabelecer uma reflexão epistemológica que contribua para que a Gestão Social não recaia na patologia da dupla consciência - uma gestão, na forma de ação social, que se credita normativamente emancipatória, mas que representa na materialidade da vida, de modo contraditório, a continuidade de uma realidade social opressora. Para tanto, após a identificação do sentido axiológico atribuído à Gestão Social e o apontamento das principais dificuldades, limitações e críticas mapeadas na literatura especializada, foram trazidas à baila duas temáticas pouco exploradas no âmbito da Gestão Social - relações de poder, consubstanciadas no conceito de colonialidade de poder, e a relação homem/natureza, delineada pelo aspecto da ecologia - a fim de demonstrar que tal gestão, uma gestão-problema, não uma gestão-resposta, deve desenvolver a capacidade de se autoproblematizar, de sentir-se como um problema e de refletir acerca de suas próprias questões não explicitadas. Ao final, após a exposição de um conjunto de caracteres epistemológicos, demonstrou-se que a Gestão Social, para não padecer das lacunas epistemológicas observadas na Gestão Estratégica, rompendo com a tendência de constituir uma antessala epistemológica, ao filtrar seletivamente as realidades observáveis e significativas e, dessa feita, mantendo a coesão social propiciada pela ideologia da gestão hegemônica, ela deve constituir a possibilidade plural de outras gestões, a partir de saberes e prática situados.

Palavras-chave: Gestão Social. Dupla consciência. Epistemologia.

\section{Abstract}

Through the notion of double consciousness, observed in the work The souls of black folk (1903), by W. E. B. Du Bois and used as a discursive meta-reference, this article, as a theoretical essay, aims to establish an epistemological

Artigo submetido em 13 de junho de 2013 e aceito para publicação em 21 de janeiro de 2014

\section{DOI: http://dx.doi.org/10.1590/1679-39519081}

1 Doutorando em Administração pela Universidade Federal de Santa Catarina - PPGA/UFSC. Endereço: Servidão Leovigildo João Vicente, 25, Sul do Rio, CEP 88140-000, Santo Amaro da Imperatriz - SC, Brasil. E-mail: justencarlos@gmail.com

2 Professor Adjunto da Universidade Federal de Santa Catarina - UFSC; Doutor em Engenharia de Produção pela UFSC. Endereço: CAD/UFSC - Universidade Federal de Santa Catarina. Campus Universitário Reitor João David Ferreira Lima, Trindade, CEP 88040970, Florianópolis - SC, Brasil. E-mail: moretto@cse.ufsc.br

3 Professor Adjunto da Universidade Federal de Santa Catarina - UFSC; Doutor em Engenharia de Produção pela UFSC. Endereço: CAD/UFSC - Universidade Federal de Santa Catarina, Campus Universitário Reitor João David Ferreira Lima, Trindade, CEP 88040970, Florianópolis - SC, Brasil. E-mail: pogarrido@cse.ufsc.br 
reflection that contributes so that Social Management does not relapse in the pathology of double consciousness - a management, in the form of social action, which names itself as normatively emancipatory, but which represents in life materiality, in a contradictory way, the continuity of an oppressive social reality. For this, after identifying the axiological sense assigned to Social Management and pointing out the main difficulties, limitations, and criticism mapped in the specialized literature, we brought forth two themes poorly explored in the Social Management domain - power relations, substantiated on the concept of power coloniality, and the relationship man/nature, delineated by the aspect of ecology in order to demonstrate that such management, a problem-management, not a response-management, must develop the ability to discuss itself, feel itself as a problem, and think through unexplained issues of its own. In the end, after exposing a set of epistemological features, it was shown that Social Management, in order to avoid suffering from the epistemological gaps observed in Strategic Management, breaking with the trend to constitute an epistemological anteroom, by selectively filtering the observable and significant realities, and, this way, keeping the social cohesion provided by the ideology of hegemonic management, it must constitute the plural possibility of other kinds of management, through situated knowledge and practice.

Keywords: Social Management. Double consciousness. Epistemology.

\section{Introdução}

A metarreferência que serve de substrato para a construção discursiva que se apresenta é a ideia de dupla consciência, tal como idealizada por W. E. B. Du Bois (1903) em The souls of black folk. Um dos precursores do movimento negro norte-americano, Du Bois foi um militante afro-americano preocupado com a construção da consciência de identidade que tinha o sujeito negro, consubstanciada na noção de dupla consciência - a clivagem entre a identificação racial construída pela opressão histórica e a concomitante associação com a modernidade eurocêntrica, via incorporação de valores disseminados pelo opressor.

Nessa dualidade entre a particularidade racial e cultural e o apego aos valores universalistas modernos, criase, na perspectiva de Du Bois (1903), um vazio, pois, na ausência de uma verdadeira autoconsciência, a consciência assumida tem de formar-se e definir-se na relação com o "outro mundo", isto é, o mundo moderno europeu. Isso possibilitou, como aponta Mignolo (2005), a negação da Europa como consciência geopolítica, mas não a negação da "europeidade" - aqui entendida como a consolidação dos valores modernos, tal como a historiografia tradicional os considera, de verve europeia -, como consciência cultural. A dupla consciência, então, ao moldar a consciência de identidade negra, expandiria uma relação colonial já existente na dimensão geopolítica - o eurocentrismo, criando uma colonialidade interna fundada na raça entre os crioullos brancos (elite local) e a população afro-americana.

A tese aqui defendida considera que a metarreferência da dupla consciência - utilizada como elemento de inspiração da artefatualidade discursiva e não como fundamento teórico -, levada ao campo da Gestão Social, propicia reflexões acerca da formação disciplinar, dos conteúdos epistemológicos, da visão ontológica e dos desafios advindos com a institucionalização do campo.

Concebida como uma dicotomia em relação à Gestão Estratégica - esta entendida como "tipo de ação social utilitarista, fundada no cálculo de meios e fins e implementada através da interação de duas ou mais pessoas na qual uma delas tem autoridade formal sobre as outras" (TENÓRIO, 2008a, p. 23) - a Gestão Social ${ }^{4}$ tem sua consciência de identidade epistêmica construída a partir da contraposição à ótica da competição e do mercado (TENÓRIO, 2010) e, portanto, vive constantemente sob o temor da dupla consciência - ao negar,

4 Entendida, para os propósitos deste artigo, como uma “[...] tentativa de não pautar os processos decisórios exclusivamente pela ótica da competição, do mercado, tal como se comporta no sistema socioeconômico em que vivemos, mas por meio de cursos de ação compreensivos, voltados para o bem comum e para o bem viver" (TENÓRIO, 2010, p. 57-58). 
no discurso de sua formação epistemológica e teórica, o universalismo reificado do management hegemônico, corre o risco de, no processo de institucionalização, deixar de refutar, no conjunto de práticas associadas à Gestão Social, a presença dos valores da ação social utilitarista.

Não obstante o espectro da dupla consciência esteja mais avivado na materialidade da Gestão Social, tal gestão, enquanto se reconheça como práxis, tem na construção teórica o outro elo e, nele, almejamos identificar duas ausências de temáticas - por coincidência ou não, constituintes dos silêncios da Gestão Estratégica -, que necessariamente devem permear a construção de uma alternativa ao management hegemônico e cuja preocupação deve, advoga-se, ser constitutiva da Gestão Social. Caso contrário, incidirá tal gestão na repetição do itinerário tradicional da hegemonia, constituindo uma antessala epistemológica, ao filtrar seletivamente as realidades observáveis e significativas e, dessa feita, manter a coesão social propiciada pela ideologia da Gestão Estratégica.

O momento presente, em que se almeja discutir os caminhos e descaminhos da Gestão Social, é oportuno para tal objetivo, ainda mais diante do esforço percebido de modelização e de transformação do caráter de processo de inovação em um produto inovador, de "[...] delimitação do campo, sobretudo na academia, definindo-se características identitárias centrais, instrumentos e metodologias próprias [...]" (BOULLOSA e SCHOMMER, 2010, p. 76).

Assim, no momento em que a Gestão Social vê-se diante do desafio de suplantar as condições materiais e concretizar-se no mundo social, a pretensão em tela é instigar o desenvolvimento teórico do campo, a partir de lacunas e silêncios identificados, os quais, sem um esforço consistente de enfrentamento, podem vir a se constituir na patologia da dupla consciência - uma gestão que, construída a partir do antimodelo mercadocêntrico, no sentido de contradição, ao desenvolver a consciência de si, internaliza valores desse antimodelo, como os silenciamentos epistemológicos e ontológicos aqui discutidos, correndo o risco de tornar-se, assim, fenômeno que, no imaginário social ${ }^{5}$ externaliza ser substantivo, mas que, na concretude material, vislumbra continuidade estratégica. Dado que, como afirma Tenório (2012, p. 27), a Gestão Social é uma "[...] mediação entre a consciência e a realidade", um esforço legítimo deve ser empreendido para evitar que tal mediação, ao se imiscuir na dupla consciência, persevere o status quo da realidade envolvente.

Por óbvio, a amplitude do esforço intentado transcende as condições deste artigo. Dessa feita, as discussões vindouras apenas constituem um escorço para futuros aprofundamentos, a ser construídos na perspectiva da dialogicidade, portanto, de forma coletiva. Em particular, adotamos o instituto da redução do conhecimento à sua essencialidade, permitindo, como advogava Ramos (1965), o posicionamento do sujeito participante, acima de tudo, como um ser cognoscente.

O percurso, nesse diapasão, envolve, em primeiro esforço, o resgate das críticas feitas à Gestão Social e, em seguida, a discussão de duas temáticas pouco presentes na construção teórica da Gestão Social - relações de poder e ecologia. Ao final, serão expostas as formas pelas quais essas temáticas contribuem para o afastamento da dupla consciência da Gestão Social, além das considerações finais.

Se, como questionou Du Bois (1903, p. 7, tradução nossa), "entre mim e o outro mundo, há sempre uma pergunta não feita [...] Como é a sensação de ser um problema?"6, a Gestão Social, sendo consciência de outra gestão possível, uma gestão-problema, não uma gestão-resposta, deve desenvolver a capacidade de autoproblematizar-se, de sentir-se como um problema e de refletir acerca de suas próprias questões não explicitadas. A sensação de ser um problema deve ser a da inconclusão perene, isto é, da humanidade em sua

\footnotetext{
${ }^{5}$ Por imaginário social, assumimos o significado expresso por Edouard Glissant, intelectual martinicano, em Poetics of relation (1997), que foi traduzido por Mignolo (2005, p. 72) como "[...] construção simbólica mediante a qual uma comunidade se define a si mesma".

6 "between me and the other world there is ever an unasked question [...] How does it feel to be a problem?"
} 
plenitude, da capacidade de pensar o mundo e pensar-se no mundo. Trazer à tona as temáticas das relações de poder e da ecologia é exercitar o pensamento acerca do mundo da Gestão Social.

\section{A Gestão Social Posta sob Parênteses Alheios}

Convém, de início, aclarar o entendimento de Gestão Social que subsidia as discussões. Declinamos, neste ponto, de resgatar os apontamentos sobre o delineamento conceitual, no que remetemos os interessados aos textos seminais, identificados em Cançado, Tenório e Pereira (2011). Central é a explicitação do sentido axiológico que damos à Gestão Social e, nesse diapasão, associamo-nos a Tenório (2008b; 2010; 2012), tratando-a como pretensão antinômica à Gestão Estratégica, esforço para orientar os processos decisórios para outros valores que não os da perspectiva mercadocêntrica e que envolvam o reconhecimento e a preocupação com o outro enquanto sujeito, em qualquer dimensão das relações sociais.

Importa, ainda, não obstante a presença contínua do sentido axiológico acima destacado, afastar a pretensa homogeneidade do termo Gestão Social, tratado amiúde no singular, quando, em realidade, tanto sob o aspecto teórico quanto na realidade empírica, é marcado pela pluralidade de correntes. Destacamos três orientações normativas, a partir do critério da aderência à discussão ora travada, sem o intento de esgotar as possibilidades alhures.

Na primeira, desenvolvida por França Filho $(2003$; 2008) e associados, a Gestão Social é apontada sob duplo aspecto - tanto representando o deslocamento do sistema de governança pública do Estado para a sociedade, mediante formas autônomas de organização do tecido social, como constituindo lógica diferenciada e combativa à gestão subordinada à lógica individualista presente na racionalidade instrumental, mediante novas formas e laços de solidariedade, alicerçados na capacidade de auto-organização da sociedade. A Gestão Social, nessa abordagem, representa o modo próprio de gestão das organizações da sociedade civil, localizadas na esfera pública não estatal.

Na segunda, caracterizada nos trabalhos de Tânia Fischer e associados, a Gestão Social do desenvolvimento é centrada na ideia do sistema de governança, "[...] poder compartilhado ou ação coletiva gerenciada" (FISCHER, 2002, p. 9), tratando-se de processo de mediação entre níveis de poder individual e social, em uma estrutura de redes embebida em contexto cultural e tendo como norte o equilíbrio entre as racionalidades instrumental e substantiva.

Na terceira, por fim, observada nos trabalhos de Tenório $(1998 ; 2006 ; 2007 ; 2008 \mathrm{a} ; 2008 \mathrm{~b}$; 2010) e associados, a Gestão Social vem a ser "[...] processo gerencial dialógico onde a autoridade decisória é compartilhada entre os participantes da ação" (TENÓRIO, 2008a, p. 40), baseado "[...] na inteligibilidade da linguagem, na dialogicidade e no entendimento esclarecido como processo, na transparência como pressuposto e na emancipação enquanto fim último" (CANÇADO, TENÓRIO e PEREIRA, 2011, p. 681). A ênfase, aqui, é a formação de processos decisórios fundamentados em outros valores, como a justiça, a igualdade participativa, a inclusão, o pluralismo, o bem viver e o bem comum, isto é, não subservientes ao mercado.

Importa ressaltar que a compreensão de tais distinções normativas é essencial a qualquer trabalho teórico ou teórico-empírico sobre Gestão Social, sob pena de invalidar as contribuições desenvolvidas, dado que a Gestão Social não é uma narrativa uniforme e homogênea, como se pressupõe à primeira vista, mas um campo socialmente construído a partir da diversidade e da heterogeneidade sociocultural presente na realidade nacional. O risco a ser evitado é o essencialismo teórico, isto é, o viés de direcionar o fenômeno a fim de que se encaixe dentro do contexto de um quadro único e integrado de referência.

Nuances como, por exemplo, a limitação da Gestão Social às organizações da sociedade civil, observada em França Filho (2003; 2008), a intenção manifesta de compatibilizar racionalidades consideradas antagônicas e 
a consideração das relações de poder, como visto em Fischer (2002), e o destaque impresso ao processo decisório, à participação e à universalidade desse tipo de gestão a qualquer dimensão institucionalizada da vida social, presente em Tenório (1998; 2006; 2007; 2008a; 2008b; 2010), devem ser reconhecidas e trabalhadas.

Na literatura sobre Gestão Social, os parênteses alheios - a reflexão crítica -, têm manifestações tanto em termos de dificuldades e limitações quanto em relação ao questionamento de seu potencial emancipatório e, grosso modo, reportam-se, explicitamente ou não, à orientação normativa de Fernando Guilherme Tenório e associados ${ }^{7}$.

As principais dificuldades e limitações foram apontadas por Tenório (2012) e Boullosa e Schommer (2009). Para o primeiro, a Gestão Social enfrenta restrições sociopolíticas e epistemológicas que a tornam uma utopia, entendida como um não conceito, uma mediação entre a consciência e a realidade, associada não com o irrealizável nem com o idealismo, mas, sim, com os "[...] atos de denunciar e anunciar. O ato de denunciar a estrutura desumanizante e o ato de anunciar a estrutura humanizadora [...]" (FREIRE, 1980, p. 27).

Do ponto de vista sociopolítico, a Gestão Social seria subserviente à realidade brasileira, que ainda não possui preocupação efetiva com o bem comum e o interesse público, em uma sociedade marcada tanto por relações intersubjetivas carregadas de ambiguidade - o jeitinho brasileiro (DAMATTA, 1989) -, quanto pela apropriação de funções, órgãos e rendas públicas por setores privados (SCHWARTZMAN, 1988). Sob o aspecto epistemológico, a Gestão Social estaria limitada pela hegemonia da racionalidade instrumental e da Gestão Estratégica.

A identificação da Gestão Social como utopia pode gerar uma série de interpretações distorcidas sobre a viabilidade de concretização do seu potencial emancipatório, especialmente diante da visão estereotipada de utopia, como fenômeno ou processo fora da realidade. Na verdade, a ideia de que a Gestão Social constitui utopia, em visão particular, reflete a preocupação conceitual de torná-la uma abordagem normativa de referência, incapaz de contaminar-se com os resquícios instrumentais presentes em uma realidade predominantemente monológica.

Boullosa e Schommer (2009), por sua vez, centrando a análise em torno do processo de rápida institucionalização do campo de práticas e pesquisas denominado Gestão Social, alertam para a crescente perda de inovação daí decorrente, tendendo a Gestão Social a se transformar em produto, não mais se caracterizando como processo. A delimitação institucional, metodológica e conceitual para a qual a Gestão Social vem caminhando, segundo as autoras, contribui para a redução do conhecimento das práticas e conceitos que poderiam enriquecer o processo de construção do campo.

Dessa feita, a Gestão Social estaria enfrentando um paradoxo, decorrente da institucionalização precoce do conceito na academia e na sociedade. A elasticidade e a imprecisão presentes no início de formação do campo e que propiciaram o seu potencial emancipatório passam a contribuir para uma modelização disciplinar, cuja consequência principal é a formação de "amarras interpretativas ou estruturas de problematização que priorizam a explicação da ação da gestão sobre a compreensão do contexto no qual se dá a ação em si” (BOULLOSA e SCHOMMER, 2009, p. 80). Essa preocupação com a institucionalização precoce do campo guarda íntima relação com a tendência de banalização do conceito. A naturalização desse conceito pode fazer com que a Gestão Social passe a ser associada com tudo o que não for Gestão Estratégica. A consequência principal disso é o empobrecimento do conceito e o descrédito no que toca aos seus resultados (PINHO, 2010; FRANÇA FILHO, 2008).

${ }^{7}$ Em grande parte, diante do pioneirismo e da predominância dessa orientação normativa. 
A principal crítica em relação à Gestão Social vem de Pinho $(2010)^{8}$, em artigo apresentado na abertura do IV Enapegs, e pode ser compreendida sob dois aspectos: terminológico e de adequação ao paradigma político-cultural brasileiro. Quanto ao primeiro, o autor entende que o termo social é convencional, ambíguo e passível de manipulação, defendendo sua substituição por algo como Gestão Emancipadora. Para Pinho (2010, p. 25), a adequação terminológica permite evitar "que o conceito não corresponda à prática ou o que efetivamente pretende ser o conceito".

No que toca ao paradigma político-cultural brasileiro, Pinho (2010) questiona a viabilidade de exercer por aqui um modelo democrático em bases efetivamente participativas, diante do panorama de extremas desigualdades de toda espécie que historicamente se formaram e da falta de qualificação técnica e política da população brasileira para a participação em instâncias deliberativas.

Nesse sentido, critica a apropriação indevida do referencial habermasiano, criado a partir da sociedade europeia, onde se faz possível a participação popular, pois presentes "instituições sólidas e estáveis, além de nível de vida elevado, baixa disparidade socioeconômica e as reconfortantes virtudes cívicas de solidariedade e de moderação" (PINHO, 2010, p. 33). Além desses apontamentos críticos, Pinho (2010) aponta que, por estar fundamentalmente voltada ao âmbito local, a Gestão Social tem possibilidade reduzida de efetivar mudanças significativas, sendo dificultado o cumprimento da promessa emancipadora em lócus espacial tão circunscrito.

Por fim, tendo em vista que o amparo epistemológico da orientação normativa de Tenório vincula-se à perspectiva habermasiana da ação comunicativa ${ }^{9}$, a Gestão Social sujeita-se às críticas tecidas ao trabalho de Habermas ${ }^{10}$, por: a) conter certos elementos antiemancipatórios, como uma ideologia intelectualista que realça a capacidade cognitiva e as habilidades de comunicação como valores centrais - quem não as tem é excluído -, e oferece um quadro de referência total, eurocêntrico, em que os anseios de emancipação afastam-se da materialidade da vida e das desigualdades materiais para abranger conteúdos meramente formais e substantivos, dissociados do quadro político-cultural das formações sociais periféricas (ALVESSON e WILMOTT, 1992; DUSSEL, 2001); b) despir do elemento crítico a negatividade e a materialidade, consideradas por Horkheimer (1990) condições necessárias para o ato libertador, tendendo, com isso, a se afastar da ideia de uma racionalidade ético-crítica que conceba a universalidade da vida a partir dos dominados e excluídos (DUSSEL, 2002); c) deixar de "institucionalizar soluções de problemas diretamente pelos cidadãos e não simplesmente promover a discussão informal com promessas de influência possíveis na arena política formal", a qual, tradicionalmente, enfrenta limitações na resolução dos problemas enfrentados pelas sociedades hodiernas (COHEN, 1998 apud FARIA, 2000, p. 55); d) conceber que o conhecimento pode ser purificado do poder, e subjetivamente emancipado, ao alcançar simetria em suas relações, vislumbrando uma relação negativa entre conhecimento e poder, pois que os aspectos ideológicos do primeiro podem ser eliminados ao se remover o segundo (ALVESSON e WILMOTT, 1992); e) interpretação dos novos movimentos sociais enquanto noção particularista e defensiva à penetração da vida social pela economia e pelo Estado, o que impede de ver nesses movimentos o caminho inverso de racionalização do mundo de vida, isto é, a concepção de uma estratégia ofensiva de consolidação do mundo da vida a partir dos movimentos sociais (JACOBI, 2000).

${ }^{8}$ A crítica de Pinho (2010) é inteiramente desenvolvida a partir dos trabalhos de Tenório. Por isso, mas não apenas, a clara distinção entre as orientações normativas da Gestão tem sua importância.

${ }^{9}$ Habermas concebe a ação social a partir da interação comunicativa, isto é, trata esta última como tipo ideal de ação social (FORESTER, 1994), marcada pelo duplo processo de i) interpretação negociada de uma definição comum da situação; e ii) do entendimento linguístico daí decorrente (HABERMAS, 2003). Na ação comunicativa, os participantes, dentro de um procedimento argumentativo, estabelecem acordo comum sobre questões vinculadas à verdade, justiça e autenticidade.

${ }^{10}$ Tais críticas não constituem esforço presente nos trabalhos que abordam a Gestão Social, mas nas obras que analisam o trabalho habermasiano propriamente dito; materializam-se, em particular, nos foros acadêmicos de discussão sobre Gestão Social, em especial nos eventos promovidos pela Rede de Pesquisadores em Gestão Social (RGS). 
Os parênteses alheios, além de restritos a uma orientação normativa da Gestão Social, não avançam, em particular, no aclaramento de dois aspectos pouco evidenciados nas discussões teóricas sobre Gestão Social, independente da orientação normativa: as relações de poder e a preocupação ecológica. Advogamos, repisase, que o enfrentamento legítimo dessas duas temáticas é precaução elementar para que a Gestão Social não sofra do espectro da dupla consciência e, destarte, represente uma antessala epistemológica da Gestão Estratégica.

\section{Colonialidade e Ecologia: Indo para Além da Dupla Consciência}

Tentemos, de pronto, apontar o que se almeja considerar no direcionamento dos esforços para a discussão acerca de colonialidade e ecologia. Por certo, ao abordar tais temáticas, estamos caminhando, em intento interdisciplinar, para além das teorias das organizações, não obstante a recursividade evidente. $\mathrm{O}$ escopo implícito é adotar a Gestão Social da capacidade de constituir legítima reflexão acerca da construção da vida humana associada, considerada a especificidade contextual de referência.

Ao abordar as relações de poder, associamo-nos à perspectiva de Quijano (2010, p. 88), entendendo poder como "[...] o espaço e uma malha de relações sociais de exploração/dominação/conflito articuladas em função, em torno, da disputa pelo controle [...]" dos seguintes constituintes da experiência social: i) trabalho e seus produtos; ii) a natureza e sua transformação produtiva; iii) o sexo, seus produtos e a reprodução da espécie humana; iv) o conhecimento e seus produtos; e v) a autoridade e seus instrumentos de coerção para a estabilidade de dado padrão de poder.

O poder, enfrentado sob a perspectiva da colonialidade, isto é, da totalidade de relações marcadas por dois caracteres elementares e recursivos - a desigualdade e a inferioridade -, na qual uma das partes, em situação desigual, é caracterizada pela outra como pretensamente inferior, irracional, primitiva ou tradicional, permite a incursão nas discussões da geopolítica do conhecimento, em substrato epistemológico, associando não apenas o controle do conhecimento com a autoridade, mas, também, avançando no entendimento da forma como se tornam cognoscíveis e visíveis os demais constituintes da experiência social.

Importa destacar que colonialidade difere de colonialismo, muito embora representem duas faces da mesma moeda. A colonialidade acarreta, necessariamente, relações raciais de poder, ao passo que o colonialismo envolve o controle da autoridade política, dos recursos de produção e do trabalho, em uma estrutura de dominação/exploração, por uma jurisdição político-administrativa externa. $\mathrm{O}$ colonialismo, pelo menos sob o aspecto formal, deixou de existir no plano das relações políticas, mas, por seu turno, persiste no plano das relações sociais, impregnado nos pensamentos, nos julgamentos e nas ações humanas, materializado na colonialidade do poder.

A colonialidade, de modo geral, é intrinsecamente associada à modernidade, esta compreendida como uma "[...] máquina geradora de alteridades que, em nome da razão e do humanismo, exclui de seu imaginário a hibridez, a multiplicidade, a ambiguidade e a contingência das formas de vida concretas [...]" (CASTROGÓMEZ, 2005, p. 169). Em contrapartida a pensadores como Habermas (1987), para os quais a modernidade ainda está em projeto e a razão dela emanada constitui autoridade condutora do homem em sociedade, associamo-nos à perspectiva da crise do projeto da modernidade, defendida, por exemplo, por Santos (1995), assimilando, em particular, que tal crise representa a ruptura "[...] de um dispositivo de poder que construía o 'outro' mediante uma lógica binária que reprimia as diferenças” (CASTRO-GÓMEZ, 2005, p. 169).

A modernidade, concebida, por seu turno, a partir da colonialidade do poder, implica o desenvolvimento de uma antessala epistemológica, ocultando, sub-repticiamente, a importância que a espacialidade tem na produção da experiência social, posto que, na maior parte das vezes, "[...] aqueles que adotam o discurso da modernidade tendem a adotar uma perspectiva universalista que elimina a importância da localização geopolítica" (MALDONADO-TORRES, 2008, p. 84). O espaço da enunciação, aquele lócus geopolítico- 
corporal do sujeito que fala e do qual se fala, dessa feita, é analiticamente menosprezado, do que decorre a tendência à desvinculação entre os sujeitos enunciador/enunciado e o lugar epistêmico de seus discursos.

Nesse sentido, o problema central na produção de alteridades que caracteriza a modernidade é a pretensão de universalização e naturalização. Dussel (2005) destaca que a concepção dominante de modernidade é eurocêntrica $^{11}$, no sentido de fenômeno europeu autogerado que se difunde ao resto do mundo ${ }^{12}$, e centrada na perspectiva da direção - da imaturidade, da ignorância e do caos -, para o desenvolvimento do ser humano, a partir da razão como esforço crítico e da noção transcendental e universal da história como progresso. O eurocentrismo deve ser visto não apenas como a visão cognitiva dos europeus, mas, principalmente, como a perspectiva da episteme formada sob sua hegemonia (QUIJANO, 2010).

Sob essa perspectiva, o progresso passou a envolver um processo no qual "[...] uma entidade ou unidade se transforma de maneira contínua, homogênea e completa em outra coisa e abandona de maneira absoluta a cena histórica" (QUIJANO, 2005). A entidade ou unidade transformada foi a civilização humana, cujo estado a transformar era o de natureza e o ponto de chegada aquele conquistado pelos europeus. A diferença entre a Europa e o outro residiu na diferenciação racial e não na dinâmica de poder.

Razão, progresso, raça e cultura tornaram-se, na modernidade, mecanismos de classificação e hierarquização de todos os povos, continentes, experiências históricas e conhecimentos (LANDER, 2005), além de ferramentas de identificação de carências e deficiências que devem ser superadas, isto é, de normalização do mundo a partir de uma visão particular - a eurocêntrica.

Dessa forma, esse eurocentrismo carrega uma episteme particular cuja lógica opera por separações e reducionismos ${ }^{13}$ e cuja legitimidade se dá por um imaginário que estabelece diferenças incomensuráveis entre o colonizador e o colonizado. Este último se torna, assim, “[...] 'o outro da razão', o que justifica o exercício de um poder disciplinar por parte do colonizador” (CASTRO-GÓMEZ, 2005).

González Stephan (1995), por exemplo, no contexto latino-americano do século XIX, associa a formação da identidade latino-americana ${ }^{14}$ a partir da perspectiva colonizadora europeia com três práticas disciplinares as constituições, os manuais de urbanidade e as gramáticas de idioma. Tais práticas, no entendimento de Castro-Gómez (2005, p. 173), possuíam em comum a materialidade escrita, que "[...] constrói leis e identidades nacionais, planeja programas modernizadores, organiza a compreensão do mundo em termos de inclusões e exclusões".

A própria ciência social, nesse contexto, representou o instrumento moderno de entendimento dessa realidade pensada em termos eurocêntricos. Dado que a principal mudança intelectual advinda com o projeto da modernidade foi a substituição da estabilidade como projeto político por uma concepção que orbitava em torno do ideal de progresso, fenômeno contínuo, sequencial, racional, organizado, controlado e eficaz, havia

${ }^{11}$ No caso da gestão, o eurocentrismo pode ser associado à perspectiva anglo-saxônica, dominante nesse enclave das relações sociais.

12 Esse entendimento é contraposto ao pensamento social latino-americano, personificado em intelectuais como Enrique Dussel, Edgardo Lander, Santiago Castro-Gómez, Anibal Quijano, Walter Mignolo, Arturo Escobar e Fernando Coronil, que defendem a dupla ideia do surgimento da modernidade a partir de transações transcontinentais cujo centro é a América e do posterior domínio do projeto moderno eurocêntrico com base na riqueza extraída do continente americano.

13 Separações absolutas ou abissais, conforme Santos (2010), como sujeito/objeto, Estado/sociedade civil, conhecimento científico/senso comum, homem/natureza, corpo/alma, moderno/colonial, bárbaro/civilizado, tempo/espaço. Reducionismos como a complexidade do mundo restrita a um empirismo matemático.

${ }^{14}$ Aqui, utilizamos o termo o adjetivo "latina" por mera conveniência e aceitação generalizada. Todavia, rejeitamos esse rótulo - cuja origem remete à política expansionista de Napoleão III e seus anseios de invadir o México -, pois obscurece "[...] toda uma nuançada, porém profunda, diversidade de núcleos civilizatórios" (DOMINGUES, 2003, p. 25-26). 
a necessidade de uma análise social científica, formada por um corpo de pesquisadores especializados e treinados, isenta de instrução moral e de valores, capaz de fornecer condições para ajustar o mundo a tal ideal (WALLERSTEIN, 2006).

A essência da colonialidade eurocêntrica, como carga epistemológica, envolve impeditivos à compreensão do mundo em que vivemos a partir do contexto cultural-político imediato e da epistemologia que lhe é própria. Considerada a colonialidade como um conjunto de pressupostos e valores universais sobre o ser humano, a riqueza, a natureza, a história, o progresso, o conhecimento e o bem viver, a análise da experiência social latino-americana não pode ser despida de uma clivagem estrutural moderno-colonial, cuja tensão a constitui e a torna inteligível.

O constrangimento e o empobrecimento epistêmico oriundo da colonialidade eurocêntrica, ao impor um conjunto analítico e conceitual estranho à realidade latino-americana, no sentido de uma perspectiva ortopédica (SANTOS, 2010), obstrui a consideração de quatro postulados epistêmicos orientadores da construção e entendimento da realidade social: primeiro, a percepção do caráter ilimitado e inesgotável da diversidade da experiência humana; segundo, a limitação dos diversos saberes existentes, cada um finito por essência, para a compreensão da infinita diversidade humana; terceiro, a validade e a pertinência de cada saber em particular, quando enquadrado nas condições situadas de sua produção e disseminação; e quarto, a concepção desses saberes não no plano abstrato, mas na concretude de práticas que possibilitam ou impedem ações no mundo real. $\mathrm{O}$ conhecimento existe apenas em uma relação ampliada, da ecologia de saberes (SANTOS, 2010).

Em particular, uma das heranças da colonialidade eurocêntrica é o tratamento dispensado à relação homem/natureza, monológica e dominadora, na qual o primeiro considera-se legítimo interventor, capaz de controle e uso das potencialidades naturais como meros recursos de produção. Tal concepção tem, entre outras, uma explicação religiosa, visto que as crenças judaico-cristãs, constituintes do eurocentrismo, consideram que Deus criou o mundo e, portanto, o mundo não é sagrado. Visto que o homem foi criado à imagem de Deus e elevado a posição superior às demais criaturas da terra, teria o legítimo direito de intervir no ambiente natural conforme suas necessidades e anseios (LANDER, 2005).

A Gestão Estratégica, enquanto forma de relação social, possui contribuição destacada para a manutenção desse padrão de relação, posto que se dinamiza mediante a racionalidade estritamente produtivista do sistema de preços, na dualidade da escassez/disponibilidade, internalizando o lucro econômico e externalizando os custos dos impactos ambientais. Assentada a discussão nesses termos, no âmbito da teoria social crítica, em uma análise da modernidade, tem-se, por um lado, a identificação e a crítica de uma forma de opressão que extrapola as relações de produção e, por outro lado, a defesa de um novo paradigma sociopolítico fundado menos na riqueza e no bem-estar material e mais na cultura e na qualidade de vida (SANTOS, 1995). Implica, ainda, sob o ponto de vista epistemológico, uma reinvenção da articulação entre ciências sociais e ciências naturais, a fim de compreender a interação entre processos naturais e sociais (SACHS, 1986).

Ademais, quando a problemática é refletida para o âmbito dos estudos organizacionais, de onde a Gestão Social tem sua gênese, a interface homem/natureza propicia uma reflexão crítica acerca da epistemologia do conhecimento organizacional, seja porque as práticas empresariais são corresponsáveis pelo iminente colapso dos recursos naturais, tendo em vista a predominância da abordagem do conhecimento e da verdade circunscrita à eficiência financeira, valorada a partir do que se produz (FOURNIER e GREY, 2000), seja porque a sustentabilidade, tomada como valor empresarial, pode servir de instrumento de legitimação para as práticas que justamente geram o colapso ecológico, quando exercida com o intento de mascarar o conjunto das externalidades negativas da atividade empresarial sobre o entorno ecológico.

A natureza, desvinculada de sua complexidade ecológica e convertida em matéria-prima do processo econômico, passa a ser codificada em termos de capital, transformando-se em uma forma de capital, o chamado capital natural. A natureza, assim, passa a ser valorizada em sua perspectiva econômica, em uma 
estratégia de naturalização da mercantilização da natureza. $\mathrm{O}$ natural se contorce, controversamente, entre o economicismo da natureza e a ecologização da economia (LEFF, ARGUETA, BOEGE et al., 2002).

Nessa direção, a relação homem/natureza precisa ser repensada, fundamentando-se na premissa de reconhecer a interdependência inerente a todos os fenômenos e no fato de que, enquanto indivíduos e sociedades, todos estamos inseridos nos processos cíclicos da natureza (CAPRA, 2006). Em outras palavras, não há predomínio de qualquer perspectiva particular, tão somente a existência de um pensamento ecológico, que percebe o mundo vivo como uma rede inseparável de relações.

É um entendimento que se afasta do antropocentrismo que caracteriza as abordagens tradicionais, deixando de conceber e tratar o ser humano ou as organizações humanas em relação assimétrica com o meio ambiente. Ainda, reconsidera o tratamento dado ao meio ambiente não mais como mero valor de uso, mas como integrante da própria vida humana (CAPRA, 2006).

Por certo, não se almeja, com isso, em contraponto a perspectivas economicistas insensíveis às limitações da biosfera, adotar um radicalismo ecológico, indiferente às necessidades produtivas humanas, até porque, como já reconheceu a ecologia cultural, o homem pode intervir de forma positiva na natureza, desde que respeite a dinâmica ecológica dos sistemas naturais e seu ciclo evolutivo (DUBOS, 1976).

Para tanto, no mínimo, a ação humana na natureza deve reunir as seguintes condições: i) as necessidades humanas concebidas autônoma e realisticamente, a partir da tradição cultural local, desprezando os chamados efeitos de demonstração modernos dos povos setentrionais (SACHS, 1986); ii) o uso positivo e produtivo das complementaridades e das sobras e quebras, da mesma forma que se dá no ecossistema natural; iii) um tratamento mais adequado dos recursos naturais, não mais vistos sob a ótica da disponibilidade e do preço, bem como dos desequilíbrios ecológicos, deixando de ser tratados apenas quando causadores de prejuízos ao processo produtivo; iv) o uso de soluções não só ecologicamente integradas, mas, também, culturalmente legitimadas, pensadas a partir dos tempos e espaços social e historicamente construídos; v) a ausência de heranças ecológicas negativas para as gerações futuras, possível a partir da baixa incidência de decisões consideradas irreversíveis, não mais passíveis de contorno pelas gerações futuras (SACHS, 1986); e vi) a participação efetiva da população nos processos decisórios.

Meio ambiente e natureza humana se revelam similares do ponto de vista analítico e dependentes do ponto de vista da materialidade da vida. Por conseguinte, a maneira mais coerente de tratamento e aproximação em relação à natureza não é "[...] por meio da dominação e do controle, mas, sim, por meio do respeito, da cooperação e do diálogo" (CAPRA, 2006, p. 158). Dessa feita, homem e natureza passam a ser concebidos como tendo um relacionamento simbiótico, em que um recorre ao outro e no qual os homens podem balizar suas ações para o uso socialmente útil e ecologicamente prudente dos recursos naturais (SACHS, 2009).

Essa interface simbiótica, contudo, somente terá concretude quando um conjunto de quatro premissas for assumido e um intenso esforço humano for despendido nesse sentido. Em primeiro lugar, o duplo princípio ético da solidariedade diacrônica com as gerações futuras - a manutenção do estado estacionário da biosfera e o respeito a sua capacidade adaptativa de evolução -, e da solidariedade sincrônica com os contemporâneos - o que implica preocupações e intervenções no que toca à justiça e equidade sociais (SACHS, 1986). A relação homem/natureza tem, em sua constituição, a natureza da relação homem/homem e as condições para a simbiose daquela residem necessariamente na experiência social de sujeitos mediados pelo mundo concreto.

Em segundo lugar, a noção de que tanto a solidariedade diacrônica quanto a sincrônica dependem de uma concepção recursiva entre comunidades humanas e comunidades ecológicas, interdependência esta exercida de forma dialógica, em espaços deliberativos "[...] onde todos têm direito à fala, sem nenhum tipo de coação" (TENÓRIO, 2006, p. 1146), pautados por valores como a inclusão, a igualdade, o pluralismo, a autonomia e orientados para o bem comum e o bem viver. Tanto a ruptura da opressão da natureza pelo homem como da opressão do homem pelo homem ocorre com o “[...] diálogo crítico e libertador [...] 
(FREIRE, 1987, p. 29), com e não para os oprimidos, em um processo que não seja apenas a liberdade para sobreviver organicamente, mas a "[...] liberdade para criar e construir, para admirar e aventurar-se" (FREIRE, 1987, p. 31). A libertação é, assim, cointencionada, tanto pelos então opressores quanto pelos então oprimidos, todos alçados à situação de sujeito, capazes de, em confronto com a realidade, "[...] não só de desvelá-la e, assim, criticamente conhecê-la, mas também de recriar este conhecimento" (FREIRE, 1987, p. 31).

Em terceiro lugar, a responsabilidade imanente a esse duplo princípio ético implica não apenas a preocupação com as ações presentes, mas, também, a consideração atribuída ao passado, ou seja, à forma como a carga histórica é registrada, transmitida, aceita e (de)formada (ENRIQUEZ, 1997). O passado passa a receber, dessa forma, uma veste emancipatória, é reconcebido como um recurso, um instrumento de inconformismo com força e redenção capaz de ser apropriado pelos oprimidos, para, em comunhão, “[...] pensar a transformação social e a emancipação sociais a partir do passado, reinventando-o e restituindo-lhe a capacidade de revelação" (SANTOS, 1997, p. 103).

Por fim, a relação homem/natureza envolve uma escala múltipla e abrangente de tempos e espaços, diametralmente oposta à escala do capitalismo de mercado e do calendário político-eleitoral. A superação dessa antinomia necessita, no mínimo, para o curto prazo, ante a carga acumulada de intervenções arbitrárias no ecossistema e a possibilidade de colapso ecológico, da opção assumida de deixar em aberto alternativas para o futuro e para aqueles que nele viverão, minimizando as mudanças irreversíveis e os danos delas decorrentes.

\section{A Consciência de Outras Gestões Possíveis: Avançando sobre as Antessalas Epistemológicas}

A Gestão Social, sendo consciência de outra gestão possível, uma gestão-problema, não uma gestão-resposta, deve desenvolver a capacidade de autoproblematizar-se, de sentir-se como um problema e de refletir acerca de suas próprias questões não explicitadas. Dessa forma deve, no mínimo, não padecer das lacunas epistemológicas observadas na Gestão Estratégica, rompendo com a tendência de constituir uma antessala epistemológica, ao filtrar seletivamente as realidades observáveis e significativas e, dessa feita, manter a coesão social propiciada pela ideologia da Gestão Estratégica. Colonialidade e ecologia foram apenas duas temáticas, dentre outras, trazidas à baila com o intento de florescer ou manter acesos os debates epistemológicos e teóricos que, no âmago, contribuam para que a Gestão Social não recaia na patologia da dupla consciência - uma gestão, na forma de ação social, que se credita normativamente emancipatória, mas que representa na materialidade da vida, de modo contraditório, continuidade de uma realidade social opressora.

Resta, para a conclusão dos esforços almejados neste artigo, demonstrar de que forma as duas temáticas abordadas - colonialidade e ecologia -, contribuem para o afastamento do espectro da dupla consciência. Faremos isso sob a perspectiva da redução do conhecimento à sua essencialidade, permitindo, como advogava Ramos (1965), o posicionamento do sujeito participante, acima de tudo, como um ser cognoscente, por intermédio de um conjunto de caracteres epistemológicos:

a) Para que efetivamente persiga o objetivo emancipatório que carrega (CANÇADO, PEREIRA e TENÓRIO, 2011), a Gestão Social necessita construir uma consciência que a afaste de uma teoria da Gestão - embora de uma gestão com normatividade diferenciada -, e a aproxime de uma teoria societal, de entendimento e construção de alternativas à realidade social. Nesse sentido, essencial se torna uma maior amplitude e proximidade, um efetivo diálogo de enfrentamento, diante dos aspectos constituintes da realidade social opressora, como a colonialidade e a relação homem/natureza, sob pena da Gestão Social reduzir e simplificar a experiência social que almeja transformar; 
b) Sob o risco de repetir o itinerário da hegemonia da gestão, a Gestão Social deve reconhecer que uma relação sujeito/sujeito, concebida em espaços decisórios com autoridade decisória compartilhada e orientada normativamente por valores como a autonomia, o pluralismo, a participação, a igualdade e o bem comum, não ocorre em abstrato, no plano da idealização, mas na materialidade concreta da vida social, onde a tendência é a negação dessa relação sujeito/sujeito, seja, dentre outros condicionantes, por uma matriz de poder caracterizada pela desigualdade e inferioridade construídas mediante alteridades - a colonialidade -, seja pela objetificação da natureza. Assim, ao almejar intervir no mundo concreto para estabelecer uma legítima relação intersubjetiva e dialógica entre sujeitos, cabe à Gestão Social, como uma gestão-problema, reconceber-se ante a concretude social, não a abstração ideal, ampliando sua carga normativa para o efetivo enfrentamento de restrições sociais como a colonialidade e o duplo viés do economicismo da natureza e da ecologização da economia;

c) Dado o caráter plural e (trans)interdisciplinar de tal esforço, a Gestão Social, rompendo com as antessalas epistemológicas, deve enunciar-se como a consciência da impossibilidade de uma gestão universal, que dê conta da complexidade da experiência social, haja vista o caráter inesgotável e ilimitado da diversidade humana e ecológica. Nesse sentido, para além de constituir a possibilidade unificada de outra gestão, importa olhar a Gestão Social como a possibilidade plural de outras gestões, construídas a partir de saberes e de práticas situados. Com isso, estariam delineadas duas barreiras ao espectro da dupla consciência: primeiro, evitando o viés de construir uma Gestão Social centrada nela mesmo, ao se abrir à procura e valorização de outras formas de ação social substantiva, ininteligíveis perante o management tradicional; segundo, por decorrência, aprofundando a crítica à Gestão Estratégica, acrescentando à antinomia valorativa o reconhecimento de sua incompletude para a leitura de uma realidade que exige múltiplas lentes praxiológicas. Se a Gestão Social almeja ser uma alternativa de construção da experiência social, não pode contentar-se com uma única visão, por mais acurada que seja; precisa reconhecer-se na possibilidade de múltiplos olhares;

d) Como saber e prática situados, a Gestão Social necessita desenvolver um duplo reconhecimento: primeiro, de que a realidade latino-americana tem, em sua gênese, a tensão colonial/moderno marcada por uma matriz de poder particular, a colonialidade, inibidora de uma relação intersubjetiva e dialógica entre sujeitos que apenas terá condições de se materializar quando tal colonialidade for enfrentada; segundo, de que, ante o princípio ecológico fundamental - a interdependência -, comunidade humana e comunidade ecológica estão intrinsecamente relacionadas e que, portanto, o homem deve lidar com a natureza da mesma forma que trata com um semelhante seu, mediante o reconhecimento de que o outro (a natureza) não é objeto, mas, sim, sujeito. $\mathrm{O}$ meio ambiente, assim como o homem, também é um sistema vivo que compartilha da mesma essencialidade, exigindo tratamento semelhante;

e) A consideração da colonialidade do poder e da ecologia é um convite para que a Gestão Social interpele a realidade social em lócus de enunciação que não tenha exclusividade sobre os saberes existentes, como tende a ser com as universidades; em outras palavras, que se espraie para "[...] todos os lugares onde o saber é convocado a converter-se em experiência transformadora" (SANTOS, 2010, p. 558), enfim, para a vida em sua diversidade humana e ecológica;

f) Na construção epistemológica e no conjunto de práticas que constituem a Gestão Social, há que se perceber a distinção entre lugar epistêmico e lugar social (GROSFOGUEL, 2008). O simples fato de algo ou alguém pensar, do ponto de vista epistêmico, contra ou alternativamente à hegemonia não significa, necessariamente, que se situe socialmente do lado oprimido das relações de poder, dado que, em particular, "[...] o êxito do sistema-mundo reside em levar os sujeitos socialmente situados no lado oprimido da diferença colonial a pensar epistemologicamente como aqueles que se encontram em posições dominantes" (GROSFOGUEL, 2008, p. 119). O remédio para a dupla consciência reside nessa diferenciação, que precisa estar bastante avivada no desenvolvimento futuro da Gestão Social para que se conserve seu potencial emancipatório. 


\section{Considerações Finais}

A Gestão Social, como consciência de outras gestões possíveis, precisa balizar-se pelo postulado - entre mim e os outros mundos, há sempre perguntas não feitas. -, reconhecendo-se como consciência de uma construção simbólica que continuamente problematiza-se e problematiza o mundo. Neste artigo, foram suscitadas duas perguntas não feitas ou, quando muito, pouco exploradas pela Gestão Social - relação homem/natureza e colonialidade do poder -, a fim de fomentar a discussão epistemológica e teórica do campo, de manter acesa a sensação de ser um problema.

A dupla consciência de Du Bois, como amparo discursivo, fundamentada nas perguntas evidenciadas, permitiu o delineamento de um conjunto de caracteres epistemológicos que, no mínimo, servem para a reflexão da Gestão Social que pretendemos. Mais do que abstratamente opor-se à Gestão Estratégica, a Gestão Social precisa intervir na materialidade da vida concreta a partir desse antagonismo. E somente fará isso ao reconhecer sua incompletude, sua impossibilidade de ser universal, sua possibilidade de dialogar e propiciar o desenvolvimento de outras gestões possíveis. Não se combate a cegueira com visão monocular.

\section{Referências}

ALVESSON, M.; WILMOTT, H. On the idea of emancipation in management and organization studies. Academy of Management Review, v. 17, n. 3, p. 432-464, July 1992.

BOULLOSA, R. F.; SCHOMMER, P. C. Gestão social: caso de inovação em políticas públicas ou mais um enigma de Lampedusa? In: RIGO, A. S. et al. (Orgs.). Gestão social e políticas públicas de desenvolvimento: ações, articulações e agenda. Recife: Univasf, 2010, 67-94 p.

CANÇADO, A. C.; TENÓRIO, F. G.; PEREIRA, J. R. Gestão social: reflexões teóricas e conceituais. Cad. EBAPE.BR, v. 9, n. 3, p. 681-703, 2011.

CAPRA, F. A teia da vida: uma nova compreensão científica dos sistemas vivos. São Paulo: Cultrix, 2006.

CASTRO-GÓMEZ, S. Ciências sociais, violência epistêmica e problema da "invenção do outro". In: LANDER, E. (Org.). A colonialidade do saber: eurocentrismo e ciências sociais - perspectivas latino-americanas. Buenos Aires: Clacso, 2005, 80-87 p.

DAMATTA, R. A casa e a rua. 3. ed. Rio de Janeiro: Rocco, 1989.

DOMINGUES, J. M. Do Ocidente à modernidade: intelectuais e mudança social. Rio de Janeiro: Civilização Brasileira, 2003.

DU BOIS, W. E. B. The souls of black folk. Chicago: A. C. McClurg \& Co., 1903.

DUBOS, R. Symbiosis of the earth and humankind. Science, v. 6, n. 193, p. 459-462, Aug. 1976.

DUSSEL, E. Hacia una filosofía política crítica. Bilbao: Desclée de Brouwer, 2001. Ética da libertação na idade da globalização e da exclusão. Petrópolis, RJ: Vozes, 2002.

Europa, modernidade e eurocentrismo. In: LANDER, E. (Org.). A colonialidade do saber: eurocentrismo e ciências sociais - perspectivas latino-americanas. Buenos Aires: Clacso, 2005, 24-32 p.

ENRIQUEZ, E. Os desafios éticos nas organizações modernas. Revista de Administração de Empresas, v. 37, n. 2, p. 6-17, Abr./Jun. 1997.

FARIA, C. F. Democracia deliberativa: Habermas, Cohen e Bohman. Lua Nova, n. 49, p. 47-68, 2000. 
FISCHER, T. M. D. A gestão do desenvolvimento social: agenda em aberto e propostas de qualificação. In: CONGRESSO INTERNACIONAL DEL CLAD SOBRE LA REFORMA DEL ESTADO Y DE LA ADMINISTRACIÓN PÚBLICA, 7., 2002, Lisboa. Anais... Lisboa: CLAD, 2002. 1-16 p.

FORESTER, J. Teoria crítica e análise organizacional. Plural, v. 1, p. 131-148, 1994.

FOURNIER, V.; GREY, C. At the critical moment: conditions and prospects for critical management studies. Human Relations, v. 53, n. 1, p. 7-32, jan. 2000.

FRANÇA FILHO, G. C. Gestão social: um conceito em construção. In: COLÓQUIO INTERNACIONAL SOBRE PODER LOCAL, 9., 2003, Salvador. Anais... Salvador: CIAGS/UFBA, 2003. 1 CD ROM.

Definindo gestão social. In: SILVA JR. J. T. (Org.). Gestão social: práticas em debate, teorias em construção. Juazeiro do Norte, CE: Ed. UFC, 2008, 27-37 p.

FREIRE, P. Conscientização: teoria e prática da libertação. 3. ed. São Paulo: Moraes, 1980.

Pedagogia do oprimido. 17. ed. São Paulo: Paz e Terra, 1987.

GONZÁLEZ STEPHAN, B. Modernización y disciplinamiento - la formación del ciudadano: del espacio público y privado. In: GONZÁLEZ STEPHAN, B. et al. (Comp.). Esplendores y miserias del siglo XIX: cultura y sociedad en América Latina. Caracas: Monte Avila, 1995.

GROSFOGUEL, R. Para descolonizar os estudos de economia política e os estudos pós-coloniais: transmodernidade, pensamento de fronteira e colonialidade global. Revista Crítica de Ciências Sociais, Coimbra, n. 80, p. 115-147, mar. 2008.

HABERMAS, J. Teoría de la acción comunicativa: racionalidad de la acción y racionalización social. Madrid: Taurus, 1987. v. 1.

Mudança estrutural da esfera pública: investigações quanto a uma categoria da sociedade burguesa. Rio de Janeiro: Tempo Brasileiro, 2003.

HORKHEIMER, M. Teoria crítica. Buenos Aires: Amorrortu, 1990.

JACOBI, P. Políticas sociais e ampliação da cidadania. Rio de Janeiro: Ed. FGV, 2000.

LANDER, E. Ciências sociais: saberes coloniais e eurocêntricos. In: LANDER, E. (Org.). A colonialidade do saber: eurocentrismo e ciências sociais - perspectivas latino-americanas. Buenos Aires: Clacso, 2005, 8-23p.

LEFF, E. et al. Más allá del desarrollo sostenible: la construcción de una racionalidad ambiental para la sustentabilidad - una visión desde América Latina. In: LEFF, E. (Comp.). La transición hacia el desarrollo sustentable: perspectivas de América Latina y el Caribe. México: INE, 2002, 477-576 p.

MALDONADO-TORRES, N. A topologia do ser e a geopolítica do conhecimento: modernidade, império e colonialidade. Revista Crítica de Ciências Sociais, Coimbra, n. 80, p. 71-114, mar. 2008.

MIGNOLO, W. D. A colonialidade de cabo a rabo: o hemisfério ocidental no horizonte conceitual da modernidade. In: LANDER, E. (Org.). A colonialidade do saber: eurocentrismo e ciências sociais - perspectivas latino-americanas. Buenos Aires: Clacso, 2005, 33-49p.

PINHO, J. A. G. Gestão social: conceituando e discutindo os limites e possibilidades reais na sociedade brasileira. In: RIGO, A. S. et al. (Orgs.). Gestão social e políticas públicas de desenvolvimento: ações, articulações e agenda. Recife: Univasf, 2010, 25-56p.

QUIJANO, A. Colonialidade do poder, eurocentrismo e América Latina. In: LANDER, E. (Org.). A colonialidade do saber: eurocentrismo e ciências sociais - perspectivas latino-americanas. Buenos Aires: Clacso, 2005, 107-130p. 
Colonialidade do poder e classificação social. In: SANTOS, B. S.; MENEZES, M. P. (Orgs.). Epistemologias do sul. São Paulo: Cortez, 2010.

RAMOS, A. G. A redução sociológica. Rio de Janeiro: Tempo Brasileiro, 1965.

SACHS, I. Ecodesenvolvimento: crescer sem destruir. São Paulo: Vértice, 1986.

A terceira margem: em busca do ecodesenvolvimento. São Paulo: Companhia das Letras, 2009.

SANTOS, B. S. Pela mão de Alice: o social e o político na pós-modernidade. São Paulo: Cortez, 1995.

. A queda do Angelus Novus: para além da equação moderna entre raízes e opções. Novos Estudos CEBRAP, n. 47, p. 103-124, mar. 1997.

Um ocidente não ocidentalista? A filosofia à venda, a douta ignorância e a aposta de Pascal. In: SANTOS, B. S.; MENEZES, M. P. (Orgs.). Epistemologias do sul. São Paulo: Cortez, 2010.

SCHWARTZMAN, S. Bases do autoritarismo brasileiro. 3. ed. Rio de Janeiro: Campus, 1988.

TENÓRIO, F. G. Gestão social: uma perspectiva conceitual. Rev. Adm. Pública, v. 32, n. 5, p. 7-23, set./out. 1998.

A trajetória do Programa de Estudos em Gestão Social (Pegs). Rev. Adm. Pública, v. 40, n. 6, p. 1145-1162, nov./dez. 2006.

(Org.). Cidadania e desenvolvimento local. Rio de Janeiro: Ed. FGV, 2007.

Um espectro ronda o terceiro setor: o espectro do mercado. 3. ed. Ijuí, RS: Unijuí, 2008a.

. (Re)visitando o conceito de gestão social. In: SILVA JR., J. T. et al. (Orgs.). Gestão social: práticas em debate, teorias em construção. Juazeiro do Norte, CE: Ed. UFC, 2008b, 39-59 p.

Gestão social: uma réplica. In: RIGO, A. S. et al. (Orgs.). Gestão social e políticas públicas de desenvolvimento: ações, articulações e agenda. Recife: Univasf, 2010, 57-62 p.

WALLERSTEIN, I. Impensar a ciência social: os limites dos paradigmas do século XIX. Aparecida, SP: Ideias \& Letras, 2006. 